Portland State University

PDXScholar

\title{
Towards the Rational Design of MRI Contrast Agents: ס-Substitution of Lanthanide(III) NB-DOTA- Tetraamide Chelates Influences but Does Not Control Coordination Geometry
}

\author{
Christiane E. Carney \\ Portland State University \\ Anh D. Tran \\ University of Texas at Dallas \\ Jing Wang \\ University of Texas at Dallas \\ Matthias C. Schabel \\ Oregon Health \& Science University \\ A. Dean Sherry
Follow this and additional,works at: https://pdxscholar.library.pdx.edu/chem_fac
University of Texas at Dallas
Part of the Chemistry Commons \\ Let us know how access to this document benefits you.
}

Citation Details

Published as: Carney, C. E., Tran, A. D., Wang, J., Schabel, M. C., Sherry, A. D., \& Woods, M. (2011). Towards the rational design of MRI contrast agents: $\delta$-substitution of lanthanide(III) NB-DOTA-tetraamide chelates influences but does not control coordination geometry. Chemistry (Weinheim An Der Bergstrasse, Germany), 17(37), 10372-10378. https://doi.org/10.1002/chem.201101007

This Post-Print is brought to you for free and open access. It has been accepted for inclusion in Chemistry Faculty Publications and Presentations by an authorized administrator of PDXScholar. Please contact us if we can make this document more accessible: pdxscholar@pdx.edu. 
Authors

Christiane E. Carney, Anh D. Tran, Jing Wang, Matthias C. Schabel, A. Dean Sherry, and Mark Woods 


\title{
Towards the Rational Design of MRI Contrast Agents: $\delta$ - Substitution of Lanthanide(III) NB-DOTA-Tetraamide Chelates Influences but Does Not Control Coordination Geometry*
}

\author{
Christiane E. Carney ${ }^{[a]}$, Anh D. Tran ${ }^{[b]}$, Jing Wang ${ }^{[b]}$, Matthias C. Schabe ${ }^{[c]}$, A. Dean \\ Sherry ${ }^{[b, d]}$, and Mark Woods ${ }^{[a, c]}$ \\ [a]Department of Chemistry, Portland State University 1719 SW 10th Ave, Portland, OR 97201 \\ (USA) mark.woods@pdx.edu \\ [b]Department of Chemistry, University of Texas at Dallas 800 W. Campbell Road, Richardson, TX \\ 75080 (USA) \\ [c]Advanced Imaging Research Center Oregon Health \& Science University 3181 S.W. Sam \\ Jackson Park Road, Portland, OR 97239 (USA) woodsmar@ohsu.edu \\ ${ }^{[d]}$ Advanced Imaging Research Center University of Texas Southwestern Medical Center Harry \\ Hines Blvd., Dallas, TX 75235 (USA)
}

\begin{abstract}
LnDOTA-tetraamide chelates (DOTA=1,4,7,10-tetraazacyclododecane-1,4,7,10-tetraacetic acid) have received considerable recent attention as a result of their potential to act as PARACEST contrast agents for magnetic resonance imaging (MRI). Although PARACEST agents afford several advantages over conventional contrast agents they suffer from substantially higher detection limits; thus, improving the effectiveness of LnDOTA-tetraamide chelates is an important goal. In this study we investigate the potential to extend conformational control of LnDOTA-type ligands to those applicable to PARACEST. Furthermore, the question of whether $\delta$ - rather than $\alpha$ substitution of the pendant arms could be used to control the chelate coordination geometry is addressed. Although $\delta$-substitution does influence coordination geometry it does not afford control. However, it can play an important role in governing the conformation of the amide substituent relative to the chelate in such as way that suggests a PARACEST agent could be designed that has detection limits at least as low as a conventional MRI contrast agent.
\end{abstract}

\section{Keywords}

conformational control; coordination modes; lanthanides; PARACEST agents; water exchange

\section{Introduction}

We have recently reported a method by which the coordination geometry adopted by $\mathrm{Ln}^{3+}$ chelates of DOTA-type ligands (DOTA=1,4,7,10-tetraazacyclododecane-1,4,7,10-tetraacetic acid) may be selected by appropriate substitution of the pendant arms and macrocyclic ring. ${ }^{[1,2]}$ LnDOTA chelates can interconvert between mono-capped square antiprism (SAP)

\footnotetext{
$\left.{ }^{[* *}\right]_{\mathrm{NB}-\mathrm{DOTA}}=2-(S)$-( $p$-nitrobenzyl)-1,4,7,10-tetraazacyclododecane-1,4,7,10-tetraacetic acid.

(C) 2011 Wiley-VCH Verlag GmbH \& Co. KGaA, Weinheim

口 Supporting information for this article is available on the WWW under http://dx.doi.org/10.1002/chem.201101007.
} 
and mono-capped twisted square antiprism (TSAP) coordination geometries either by a flip in the conformation of the macrocyclic ring or a reorientation of the pendant arms. ${ }^{[3,4]}$ Substitution can effectively halt these intramolecular processes affording a single coordination geometry. ${ }^{[1,2]}$ The coordination geometry thus obtained is then determined by the relative configuration of the substituents on the macrocyclic ring and the pendant arms; when the configurations at these two locations are the same, a TSAP isomer results and when they are opposed, a SAP isomer results. ${ }^{[1,2]}$ The selection of coordination geometry in this type of chelate is of interest since it may facilitate the design of more effective $\mathrm{Gd}^{3+}$ based MRI contrast agents. TSAP isomers have consistently been found to have water exchange rates that are $50-100$-fold faster than those of SAP isomers, ${ }^{[5-7]}$ a critical factor in the behavior of $\mathrm{Gd}^{3+}$-based contrast agents. LnDOTA-tetraamide chelates exhibit a similar coordination chemistry to DOTA chelates but much slower water proton exchange kinetics as a result of the reduced electron density on the central metal ion. These slower exchange rates have sparked interest in this class of chelate as potential PARACEST (paramagnetic chemical exchange saturation transfer) agents. ${ }^{\left[{ }^{[, 9]}\right.}$ Since slow exchange is desirable for PARACEST, SAP isomers are generally preferred. It has been observed that LnDOTAtetraamides with more bulky amide substituents have a general preference for the SAP coordination geometry, but recent results suggest that changes in the local environment, and in particular the solvent, may cause changes in the coordination chemistry of LnDOTAtetraamide chelates. ${ }^{[10]}$ Furthermore, addition of a second amide substituent seems to increase the proportion of TSAP isomer present. ${ }^{[10]}$ In light of these observations, we were interested to know whether it was possible to selectively control the coordination geometry of DOTA-tetraamide chelates through substitution in a manner analogous that used for DOTA chelates. Of particular interest was the effect of introducing chirality into the $\delta$ position of an amide substituent of the pendant arm rather than in the $\alpha$-position as employed previously with DOTA chelates. The motivation for this approach is that $\alpha$ substitution necessarily involves a synthetic transformation at a chiral center, with all the attendant problems. Control from the $\delta$-position would eliminate these synthetic complications. Chiral amide substituents have been reported to influence both the orientation of pendant arms and configuration at phosphorus in triphosphinate-monoamide chelates. ${ }^{[11]}$ The question we sought to address in this work is whether, in DOTA-tetraamide systems, this approach would not merely influence the orientation of the pendant arms but define it.

\section{Results and Discussion}

EuDOTAM-Gly has been widely studied as a potential PARACEST agent ${ }^{[12-14]}$ and, given its potential suitability for use in vivo, ${ }^{[15,16]}$ was therefore an ideal starting point for this investigation. The conformation of the macrocyclic ring was 


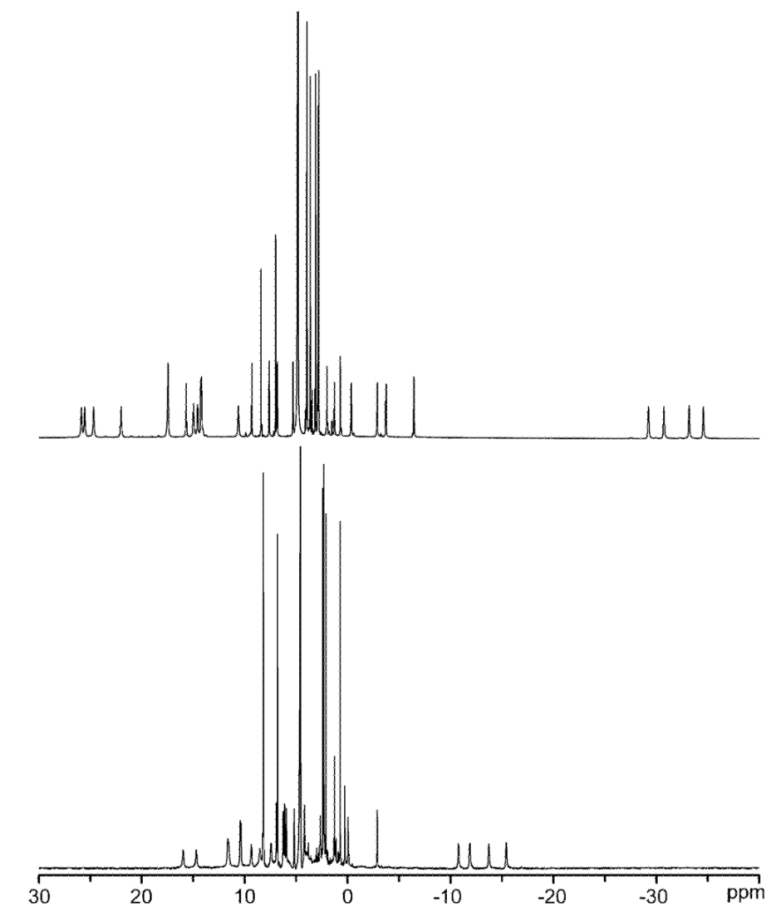

controlled with the same nitrobenzyl substituent employed in our previous systems ${ }^{[1,2]}$ _an $S$ - configuration conferring a $(\delta \delta \delta \delta)$ conformation upon the macrocyclic ring. Alanine was substituted for glycine in the synthesis of the pendant arms. $(R)$-alanine ethyl ester and $(S)$ alanine benzyl ester were used to prepare the two diastereoisomeric ligands $S-R R R R-\mathbf{1}$ and $S$-SSSS-1 (Scheme 1). In each case the alanine ester was condensed with bromoacetyl bromide in $\mathrm{CH}_{2} \mathrm{Cl}_{2}$ with $\mathrm{K}_{2} \mathrm{CO}_{3}$ as base. The resulting bromoacetamides were then used to alkylate the $S$-2-nitrobenzyl cyclen. Ester cleavage-saponification for the ethyl esters and $\mathrm{BCl}_{3}$ in $\mathrm{CH}_{2} \mathrm{Cl}_{2}$ in the case of benzyl esters ${ }^{[17]}$ _ afforded $S-R R R R-\mathbf{1}$ and $S$-SSSS-1. The $\mathrm{Ln}^{3+}$ chelates were then prepared from the corresponding $\mathrm{Ln}^{3+}$ triflate in water at $\mathrm{pH} 6$ and purified by preparative RP-HPLC (C18) to afford each chelate in its protonated form.

The coordination geometry of DOTA and DOTA-tetraamide type chelates are known to be strongly affected by the ionic radius of the $\mathrm{Ln}^{3+}$ ion. A preference for the TSAP geometry is observed for earlier (larger) $\mathrm{Ln}^{3+}$ ions, switching to the SAP geometry as the ionic radius decreases across the series. ${ }^{[18,19]}$ To account for the effect of ionic radius the $\mathrm{Pr}^{3+}, \mathrm{Eu}^{3+}$, and $\mathrm{Yb}^{3+}$ chelates of each ligand were prepared and examined by ${ }^{1} \mathrm{H}$ NMR spectroscopy. In the case of $\mathrm{Pr}^{3+}$, only one coordination geometry could be detected for each chelate (Figure 1), indicating that, as expected, the $S$-RRRR-isomer adopts the $\Lambda(\delta \delta \delta \delta)$ SAP coordination geometry and the $S$-SSSS-isomer is in the $\Delta(\delta \delta \delta \delta)$ TSAP conformation, exclusively.

Reducing the ionic radius of the $\mathrm{Ln}^{3+}$ ion $\left(\mathrm{Pr}^{3+} \rightarrow \mathrm{Eu}^{3+} \rightarrow \mathrm{Yb}^{3+}\right)$ was found to have no effect on the chelates of $S-R R R R-\mathbf{1}$, which were found to exist in only one coordination geometry (the $\Lambda(\delta \delta \delta \delta$ ) conformation) across the lanthanide series (Figure 1, 2, and 3). In contrast, the chelates of $S$-SSSS-1 were found to be profoundly affected by changing the ionic radius of the $\mathrm{Ln}^{3+}$ ion with increasing amounts of chelate in a SAP coordination geometry being discernable in the NMR spectrum of the $\mathrm{Eu}^{3+}$ and $\mathrm{Yb}^{3+}$ chelates (Figure 2 and Figure 3). For EuS-SSSS-1 the amount of SAP isomer observed is quite small, approximately 5\%, but for $\mathrm{YbS}$-SSSS-1 the amount increases to almost $50 \%$. It is also notable that considerable line broadening can be observed in the spectrum of the TSAP isomer of EuS-SSSS-1, but not the $\mathrm{SAP}$ isomer. The line broadening is also not observed in the corresponding $\mathrm{Yb}^{3+}$ chelate. The origin of this effect remains obscure but perhaps relates to an increase in internal 
vibrational or torsional motions in the ligand, shortening $\mathrm{T}_{2}$, as it attempts, but fails, to overcome the energy barrier associated with isomeric exchange.

For a chelate of S-SSSS-1 to adopt a SAP coordination geometry, either the macrocyclic ring or the pendant arms must adopt a conformation that opposes the configuration of the chiral center located on that group. A flip in the conformation of the macrocyclic ring would place the nitrobenzyl substituent in an axial position, substantially increasing the torsional strain in the system and may be considered highly unlikely. Rather it seems that the SAP form arises from the pendant arms rotating into the unexpected conformation ( $\Lambda$ rather than $\Delta$ for the $S$ SSSS-isomer). ${ }^{[20]}$ In an $\alpha$-substituted system, torsional strain is minimized by placing the substituent as far from the metal (trans- across the $\mathrm{N}-\mathrm{C}_{\alpha}$ bond) as possible (Figure 4). This determines the orientation of the pendant arms. The origins of control observed in some $\delta$ substituted systems remain ambiguous; however, a survey of crystallographic data on related systems suggests that a preferred conformation exists. ${ }^{[11,21-27]}$ It appears that the lowest energy conformation points the hydrogen of the chiral center towards the metal ion, the bulkiest substituent is then placed in a pseudo-equatorial position relative to the chelate (Figure 4). This can occur only if the pendant arms are orientated appropriately: $\Lambda$ for an $R$ configuration, $\Delta$ for $S$-configuration. If the arms rotate and adopt the opposite orientation, then the bulky substituent is placed in a pseudo-axial position that is presumably higher in energy (Figure 4). Examples of this situation in the crystallographic literature suggest that this occurs primarily when a second factor forces the arms into the orientation that opposes the configuration of the chiral substituent. ${ }^{[21]}$ It seems likely that the decrease in ionic radius, and perhaps the associated increase in charge density, contributes to an increase in this second factor for $\mathrm{LnS}$-SSSS-1 chelates as one passes along the $\mathrm{Ln}^{3+}$ series. All LnDOTAM-Gly chelates exhibit an exclusive preference for the SAP geometry and although the reasons for this are unclear, it does explain why no TSAP isomer was observed for any of the $\mathrm{LnS}-R R R R-\mathbf{1}$ chelates, even for $\mathrm{Pr}^{3+}$ which often exhibits a preference for this co-ordination geometry. This phenomenon, which drives LnDOTAM-Gly chelates into exclusively SAP geometries, is presumably the same as that which results in SAP isomers being observed for the LnS-SSSS-1 chelates. The SAP isomer that is observed would be the same $\Lambda(\delta \delta \delta \delta)$ conformation observed for the $\operatorname{Ln} S$-RRRR-1 chelates but with one significant difference: the carboxylate substituent must occupy a pseudo-axial rather than a pseudoequatorial position.

Although the substitution of the $\delta$-position does not afford control over the coordination geometry in LnS-SSSS-1 chelates, preliminary results suggest that the intramolecular exchange processes between the two coordination geometries have been "frozen out". No evidence of exchange could be detected by EXSY or by saturation transfer experiments on the highly shifted acetate peaks of YbS-SSSS-1, suggesting that the two isomers (SAP and TSAP) are either not in exchange or exchange so slowly that the process cannot be detected by these techniques.

From the point of view of PARACEST agent design, chelates that adopt a SAP coordination geometry are preferred because, in general, they possess slower water proton exchange kinetics. The unexpected appearance of a second conformer of the SAP coordination geometry, that adopted by EuS-SSSS-1, afforded a unique opportunity to examine how the orientation of the carboxylate group affects CEST. NMR samples were prepared to compare the CEST of EuS-RRRR-1 with that of EuS-SSSS-1 at 1) the same overall concentration of chelate $(274 \mu \mathrm{m})$ and 2$)$ the same concentration of SAP isomer $(13.7 \mu \mathrm{m})$ (Figure 5). CEST peaks at approximately $+50 \mathrm{ppm}$ were observed for both chelates: $52 \mathrm{ppm}$ for EuS-RRRR-1 and $49 \mathrm{ppm}$ for EuS-SSSS-1, consistent with CEST arising from a SAP coordination geometry in each case. When the overall chelate concentration $\left(\left[\mathrm{Eu}^{3+}\right]\right)$ is the same, the magnitude of CEST arising from EuS-RRRR-1 is approximately threefold greater than that 
of EuS-SSSS-1 (Figure 5, open symbols), but the SAP isomer constitutes only 1/20 of the EuS-SSSS-1 chelate. When the concentrations of the SAP isomer in each sample were normalized ( $[\mathrm{SAP}]=13.7 \mu \mathrm{m}$ ), no CEST was observed from Eu-S-RRRR-1, whereas EuSSSSS-1 produces a change in bulk water signal of approximately 10\% (Figure 5, circles). Clearly the SAP isomer of EuS-SSSS-1 is a substantially more effective PARACEST agent than that of EuS-RRRR-1.

To better understand the difference between these two SAP isomers these CEST data were quantitatively analyzed. In general CEST spectra may be fitted to the Bloch equation modified for exchange, ${ }^{[28]}$ however, a reasonable fit between this model and the data for EuS-SSSS-1 could not be obtained when the concentration of water shifted to +49 ppm was the same as that of the SAP isomer (see Figure S2 in the Supporting Information). The water proton residence lifetime $\left(\tau_{M}{ }^{H}\right)$ for the SAP isomer of each chelate was therefore determined independently by the so-called $\omega$-method', [29] affording values of $\tau_{\mathrm{M}}{ }^{\mathrm{H}}=116 \mu \mathrm{s}$ $(E u S-R R R R-1)$ and $65 \mu \mathrm{s}(\mathrm{EuS}-S S S S-1)$ (Figure 6). These values could then be applied to modeling the data to the modified Bloch equations. The spectrum of Eu-S-RRRR-1 fitted to theory satisfactorily (Figure 5), however, the spectrum of EuS-SSSS-1 continued to prove difficult to fit. A satisfactory fit for these data could only be obtained when the concentration of protons in the highly shifted pool $(+49 \mathrm{ppm})$ was allowed to increase beyond the concentration of the SAP isomer. When the concentration of water molecule in this pool was 3.7 times that of the SAP isomer a good fit was obtained suggesting that between two and three additional water molecules may be present in the highly shifted pool of EuS-SSSS-1 (Figure 5). These additional water molecules must be closely held and highly shifted by $\mathrm{Eu}^{3+}$, although perhaps not so highly shifted as the coordinated water, which may account for the slightly smaller shift of the CEST peak in this chelate. These additional water protons would certainly explain why the SAP isomer of EuS-SSSS-1 is a much more effective PARACEST agent than EuS-RRRR-1.

Although two conformational isomers (pseudo-axial/equatorial) have been postulated previously ${ }^{[11]}$ the two diastereoisomeric chelates of Eu1 have for the first time afforded an opportunity to examine the CEST properties of each. The S-SSSS (pseudo-axial) isomer is a significantly more effective PARACEST agent possibly because it closely holds more than one water molecule in a highly shifted pool. In such a situation the value of $\tau_{\mathrm{M}}{ }^{\mathrm{H}}$ reflects all protons in this pool, it is therefore difficult to understand exactly how the exchange kinetics of these chelates modulate CEST.

These results demonstrate, for the first time, that it may be possible to design PARACEST agents that have detection limits for MRI comparable to current MRI contrast agents. In Figure $4 \mathrm{EuS}$-SSSS-1 generates about 10\% CEST at an overall chelate concentration of

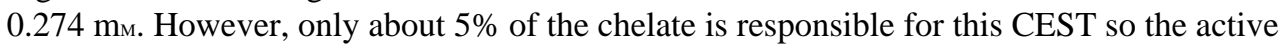
concentration is just $13.7 \mu \mathrm{m}$, but these measurements are in only $10 \%$ water in acetonitrile. Assuming a linear relationship between CEST and concentration (which is approximately true at very low concentrations), ${ }_{[30]} 137 \mu \mathrm{m}$ could generate $10 \%$ CEST. A change in water signal intensity of only about $3 \%$ is required to observe contrast changes in an MR image, so just $46 \mu \mathrm{m}$ of the SAP isomer of EuS-SSSS-1 should afford an MRI detectable level of CEST in pure water.

Although these measurements were performed by using admittedly high $\mathrm{B}_{1}$ powers (upwards of $1 \mathrm{kHz}$ ) there is scope for $\mathrm{B}_{1}$ to be substantially reduced before the detection limit of the active form of this agent exceeds $0.1 \mathrm{~m}_{\mathrm{M}}$, the typical dose of a clinical MRI contrast agent $\left(0.1 \mathrm{mmol} \mathrm{kg}^{-1}\right)$. Clearly further experimentation is required to better understand the potential of the type of system for PARACEST design. Nonetheless, these preliminary data do suggest that attending to the coordination chemistry of LnDOTA- 
tetraamide chelates may provide a means by which the detection limit problem in CEST may be overcome.

\section{Experimental Section}

\section{General remarks}

All solvents and reagents were purchased from commercial sources and used as received except where noted. 'Water' refers to deionized water with a resistivity of $\left\langle 18.2 \mathrm{M} \Omega \mathrm{cm} .{ }^{1} \mathrm{H}\right.$ and ${ }^{13} \mathrm{C}$ NMR spectra were acquired on a JOEL Eclipse 270 spectrometer operating at 270.17 and $67.94 \mathrm{MHz}$, respectively. CEST spectra were acquired on a Bruker Avance IIa 400 spectrometer operating at $400.13 \mathrm{MHz}$. Infrared spectra were recorded on a Nicolet Avatar 360 FTIR spectrophotometer. Melting points were recorded on a Fisher-Johns melting point apparatus and are uncorrected. RP-HPLC purification was performed on a Waters $\delta$-prep HPLC system using a 30×250 mm Phenomenex Luna C18(2) column. In all cases ligands were purified by eluting for $5 \mathrm{~min}$ of $100 \%$ water $(0.037 \% \mathrm{HCl})$ followed by a linear gradient over $35 \mathrm{~min}$ to $40 \%$ acetonitrile and $60 \%$ water $(0.037 \% \mathrm{HCl})$ at a flow rate of $30 \mathrm{~mL} \mathrm{~min}^{-1}$. Chelates were purified by eluting for $5 \mathrm{~min}$ with $100 \%$ water $(0.037 \%$

$\mathrm{HCl})$ followed by a linear gradient over $35 \mathrm{~min}$ to $10 \%$ acetonitrile and $90 \%$ water $(0.037 \%$ $\mathrm{HCl})$ at a flow rate of $30 \mathrm{~mL} \mathrm{~min}^{-1}$. Elution of products was monitored by $\mathrm{UV}$ absorbance at 210 and $270 \mathrm{~nm}$.

\section{(R)-N-(Ethyl-2-propionate) bromoacetamide (2)}

To a solution of bromoacetyl bromide $(2.40 \mathrm{~mL}, 26.3 \mathrm{mmol})$ in dichloromethane $(100 \mathrm{~mL})$ was added potassium carbonate $(6.04 \mathrm{~g}, 43.8 \mathrm{mmol})$ and the resulting suspension was cooled to $0^{\circ} \mathrm{C}$. A solution of $(R)$-alanine ethyl ester $(2.57 \mathrm{~g}, 21.9 \mathrm{mmol})$ in dichloromethane $(50$ $\mathrm{mL}$ ) was added dropwise over a period of $20 \mathrm{~min}$. The mixture was stirred for a further 30 min at $0^{\circ} \mathrm{C}$ and 18 more hours at room temperature. Water $(30 \mathrm{~mL})$ was added cautiously and the two layers separated. The aqueous phase was extracted with dichloromethane (50 $\mathrm{mL}$ ), the organic phases were combined, dried $\left(\mathrm{Na}_{2} \mathrm{SO}_{4}\right)$, and the solvents removed under reduced pressure. The residue was taken up into a minimum of dichloromethane and recrystallized by addition ethyl ether and hexanes at $-20^{\circ} \mathrm{C}$ to afford a colorless solid (1.98 g 38\%). M.p. $66-67^{\circ} \mathrm{C} ;{ }^{1} \mathrm{H} \mathrm{NMR}\left(\mathrm{CDCl}_{3}, 270 \mathrm{MHz}\right): \delta=7.13$ (s br, $\left.1 \mathrm{H}, \mathrm{NH}\right), 4.52$ $\left(\mathrm{dq},{ }^{3} \mathrm{~J}_{\mathrm{HH}}=7 \mathrm{~Hz},{ }^{3} J_{\mathrm{HH}}=7 \mathrm{~Hz}, 1 \mathrm{H}, \mathrm{NHCHCH}_{3}\right), 4.26\left(\mathrm{q},{ }^{3} J_{\mathrm{HH}}=8 \mathrm{~Hz}, 2 \mathrm{H}, \mathrm{OCH}_{2} \mathrm{CH}_{3}\right), 3.82(\mathrm{~s}$, $\left.2 \mathrm{H}, \mathrm{BrCH}_{2}\right), 1.45\left(\mathrm{~d},{ }^{3} \mathrm{~J}_{\mathrm{HH}}=7 \mathrm{~Hz}, 3 \mathrm{H}, \mathrm{CHCH}_{3}\right), 1.27 \mathrm{ppm}\left(\mathrm{t},{ }^{3} \mathrm{~J}_{\mathrm{HH}}=8 \mathrm{~Hz}, 3 \mathrm{H}, \mathrm{CH}_{2} \mathrm{CH}_{3}\right) ;{ }^{13} \mathrm{C}$ NMR $\left(\mathrm{CDCl}_{3}, 68 \mathrm{MHz}\right): \delta=171.6(\mathrm{C}=\mathrm{O}), 164.5(\mathrm{NHC}=\mathrm{O}), 60.1\left(\mathrm{OCH}_{2}\right), 47.8\left(\mathrm{BrCH}_{2}\right)$, $27.6(\mathrm{CH}), 17.3\left(\mathrm{OCH}_{2} \mathrm{CH}_{3}\right), 13.4 \mathrm{ppm}\left(\mathrm{CHCH}_{3}\right) ; v_{\max }(\mathrm{KBr} \operatorname{disc})=3743(\mathrm{NH}), 1738\left(\mathrm{CO}_{2}\right)$, $1647 \mathrm{~cm}^{-1}(\mathrm{NHC}=\mathrm{O}) ; \mathrm{m} / z(\mathrm{ESMS} \mathrm{EI}-): 236\left(100 \%,\left[M^{-} \mathrm{H}^{+}\right]^{-}\right)$, appropriate isotope patterns were observed.

\section{(S)-N-(Benzyl-2-propionate) bromoacetamide (3)}

L-Alanine benzyl ester hydrochloride $(4.0 \mathrm{~g}, 18.5 \mathrm{mmol})$ was dissolved in water $(20 \mathrm{~mL})$ and sodium carbonate added until the solution $\mathrm{pH}$ exceeded 12 . The solution was then extracted with dichloromethane $(2 \times 200 \mathrm{~mL})$. The organic extracts were combined, dried $\left(\mathrm{Na}_{2} \mathrm{SO}_{4}\right)$, and the solvents were removed under reduced pressure. The residue was taken up into dichloromethane $(50 \mathrm{~mL})$ and the resulting solution added dropwise to a solution of bromoacetyl bromide $(2.0 \mathrm{~mL}, 22.2 \mathrm{mmol})$ in dichloromethane $(100 \mathrm{~mL})$ containing potassium carbonate $(5.11 \mathrm{~g}, 37.0 \mathrm{mmol})$ and cooled to $0^{\circ} \mathrm{C}$ in an ice-bath. Addition was carried out over a period of $20 \mathrm{~min}$ and the reaction stirred for a further $30 \mathrm{~min}$ at $0^{\circ} \mathrm{C}$. The reaction mixture was allowed to warm to room temperature and stirred for $18 \mathrm{~h}$ at ambient temperature. Water $(30 \mathrm{~mL})$ was added cautiously and the two layers separated. The aqueous phase was extracted with dichloromethane $(50 \mathrm{~mL})$, the organic phases were combined, dried $\left(\mathrm{Na}_{2} \mathrm{SO}_{4}\right)$, and the solvents removed under reduced pressure. The residue 
was taken up into a minimum of dichloromethane and recrystallized by addition ethyl ether and hexanes at $-20^{\circ} \mathrm{C}$ to afford a colorless solid $\left(3.44\right.$ g, 62\%). M.p. $59-61{ }^{\circ} \mathrm{C} ;{ }^{1} \mathrm{H}$ NMR $\left(\mathrm{CDCl}_{3}, 270 \mathrm{MHz}\right): \delta=7.34(\mathrm{~m}, 5 \mathrm{H}, \mathrm{Ar}), 7.06(\mathrm{~s} \mathrm{br}, 1 \mathrm{H}, \mathrm{NH}), 5.12\left(\mathrm{~d},{ }^{2} J_{\mathrm{HH}}=10 \mathrm{~Hz}, 1 \mathrm{H}\right.$, aa' system, $\left.\mathrm{ArCH}_{2}\right) 5.11\left(\mathrm{~d},{ }^{2} J_{\mathrm{HH}}=10 \mathrm{~Hz}, 1 \mathrm{H}\right.$, aa system, $\left.\mathrm{ArCH}_{2}\right), 4.6\left(\mathrm{dq},{ }^{3} J_{\mathrm{HH}}=7 \mathrm{~Hz},{ }^{3} J_{\mathrm{HH}}=7\right.$ $\left.\mathrm{Hz}, 1 \mathrm{H}, \mathrm{NHCHCH}_{3}\right), 3.82\left(\mathrm{~s}, 2 \mathrm{H}, \mathrm{BrCH}_{2}\right), 1.47 \mathrm{ppm}\left(\mathrm{d},{ }^{3} \mathrm{~J}_{\mathrm{HH}}=7 \mathrm{~Hz}, 3 \mathrm{H}, \mathrm{CH}_{3}\right) ;{ }^{13} \mathrm{C} \mathrm{NMR}$ $\left(\mathrm{CDCl}_{3}, 68 \mathrm{MHz}\right): \delta=172.4\left(\mathrm{CO}_{2}\right), 165.6(\mathrm{NHC}=\mathrm{O}), 135.2(\mathrm{Ar}), 129.9(\mathrm{Ar}), 129.1(\mathrm{Ar})$, $128.4(\mathrm{Ar}), 67.7\left(\mathrm{ArCH}_{2}\right), 49.2\left(\mathrm{BrCH}_{2}\right), 29.4(\mathrm{CH}), 18.7 \mathrm{ppm}\left(\mathrm{CH}_{3}\right) ; v_{\max }(\mathrm{KBr} \operatorname{disc}): 1734$ $\left(\mathrm{CO}_{2}\right), 1717\left(\mathrm{CO}_{2}\right), 1653 \mathrm{~cm}^{-1}(\mathrm{NHC}=\mathrm{O}) ; \mathrm{m} / z(\mathrm{ESMS} \mathrm{EI}-): 298\left(100 \%,\left[M^{-} \mathrm{H}^{+}\right]^{-}\right)$an appropriate isotope pattern was observed.

\section{(1R, 4R, 7R, 10R)-ס, $\delta^{\prime}, \delta^{\prime \prime}, \delta^{\prime \prime \prime}-$ Tetramethyl-[2-(S)-(p-nitrobenzyl)-1,4,7,10- tetraazacyclododecane]-1,4,7,10-tetraacetateacetamide $\left(\mathrm{H}_{4} \mathrm{~S}-\mathrm{RRRR}-\mathbf{1}\right)$}

$2-S$-( $p$-Nitrobenzyl) cyclen $(150 \mathrm{mg}, 0.49 \mathrm{mmol})$ and the bromoacetamide $2(581 \mathrm{mg}, 2.44$ $\mathrm{mmol}$ ) were dissolved in acetonitrile $(30 \mathrm{~mL})$, and potassium carbonate $(337 \mathrm{mg}, 2.44$ mmol) was added. The resulting suspension was heated under reflux with stirring for seven days. The solvents were then removed under reduced pressure and the residue taken up into water $(20 \mathrm{~mL})$ and dichloromethane $(100 \mathrm{~mL})$. The two layers were separated and the aqueous phase extracted with dichloromethane $(2 \times 50 \mathrm{~mL})$. The organic phases were combined, dried $\left(\mathrm{Na}_{2} \mathrm{SO}_{4}\right)$, and the solvents removed under reduced pressure. The residue was taken up into tetrahydrofuran $(5 \mathrm{~mL})$ and water $(10 \mathrm{~mL})$ and a $1 \mathrm{M}$ sodium hydroxide solution $(2.4 \mathrm{~mL})$ added. The resulting monophasic solution was heated to $60^{\circ} \mathrm{C}$ for $48 \mathrm{~h}$. The solvents were removed under reduced pressure and the residue taken up into water and the $\mathrm{pH}$ adjusted to 7 with $\mathrm{HCl}$ prior to RP-HPLC purification. After lyophilization of the solvents the dihydrochloride salt of title compound was obtained as a colorless solid (147 $\mathrm{mg}, 30 \%)$. $\mathrm{R}_{\mathrm{T}}=27.79 \mathrm{~min}$; m.p. $>170{ }^{\circ} \mathrm{C} ;{ }^{1} \mathrm{H} \mathrm{NMR}\left(\mathrm{D}_{2} \mathrm{O}, 270 \mathrm{MHz}\right): \delta=8.11\left(\mathrm{~d},{ }^{3} J_{\mathrm{HH}}=8 \mathrm{~Hz}\right.$, $2 \mathrm{H}, \mathrm{Ar}), 7.40$ (d, $\left.{ }^{3} J_{\mathrm{HH}}=8 \mathrm{~Hz}, 2 \mathrm{H}, \mathrm{Ar}\right), 2.66-4.43$ (m br, $29 \mathrm{H}$, ring $\mathrm{NCH}_{2}, \mathrm{CH}_{2} \mathrm{C}=\mathrm{O}, \mathrm{CH}_{2} \mathrm{Ar}$, $\left.\mathrm{CHCH}_{3}\right), 1.31 \mathrm{ppm}\left(\mathrm{m}, 12 \mathrm{H}, \mathrm{CHCH}_{3}\right) ; \mathrm{m} / z$ (ESMS EI+): $824\left(100 \%\right.$, [M+H $\left.\left.{ }^{+}\right]\right) ; v_{\max }(\mathrm{iTR})$ : $3023(\mathrm{NH}), 1733\left(\mathrm{CO}_{2}\right), 1656(\mathrm{C}=\mathrm{ONH}), 1546,1519,1454,1346,1210,1157,943,735$ $\mathrm{cm}^{-1}$.

(1S, 4S, 7S, 10S)-ס, $\delta^{\prime}, \delta^{\prime \prime}, \delta^{\prime \prime \prime}-$ Tetramethyl-[2-(S)-(p-nitrobenzyl)-1,4,7,10tetraazacyclododecane]-1,4,7,10-tetraacetateacetamide $\left(\mathrm{H}_{\mathbf{4}} \mathrm{S}\right.$-SSSS-1)

2-S-( $p$-Nitrobenzyl) cyclen $(250 \mathrm{mg}, 0.81 \mathrm{mmol})$ and the bromoacetamide $\mathbf{3}(1.22 \mathrm{~g}, 4.07$ $\mathrm{mmol}$ ) were dissolved in acetonitrile $(30 \mathrm{~mL})$, and potassium carbonate $(562 \mathrm{mg}, 4.07$ mmol) was added. The resulting suspension was heated under reflux with stirring for seven days. The solvents were then removed under reduced pressure and the residue taken up into water $(20 \mathrm{~mL})$ and dichloromethane $(100 \mathrm{~mL})$. The two layers were separated and the aqueous phase extracted with dichloromethane $(2 \times 50 \mathrm{~mL})$. The organic phases were combined, dried $\left(\mathrm{Na}_{2} \mathrm{SO}_{4}\right)$, and the solvents removed under reduced pressure. The residue was taken up into dry chloroform $(10 \mathrm{~mL}) ; 5 \mathrm{~mL}$ of the resulting solution was transferred to a reaction flask which was purged with argon. The reaction mixture was cooled to $-10^{\circ} \mathrm{C}$ in a salt/ice-bath, and a $1_{\mathrm{M}}$ solution of $\mathrm{BCl}_{3}$ in dichloromethane $(1.6 \mathrm{~mL})$ was added. After addition the reaction mixture was allowed to warm to ambient temperature and was then stirred for $14 \mathrm{~h}$. Water $(2 \mathrm{~mL})$ was added dropwise to quench the reaction, followed by $1_{\mathrm{M}}$ $\mathrm{HCl}(8 \mathrm{~mL})$ and the ligand was extracted into the aqueous phase. The ligand solution was used directly to purify the title compound by RP-HPLC. After lyophilization of the solvents the dihydrochloride salt of title compound was obtained as a colorless solid (78.4 mg, 20\%). $\mathrm{R}_{\mathrm{T}}=25.94 \mathrm{~min}$; m.p. $>170^{\circ} \mathrm{C} ;{ }^{1} \mathrm{H} \mathrm{NMR}\left(\mathrm{D}_{2} \mathrm{O}, 270 \mathrm{MHz}\right): \delta=8.21\left(\mathrm{~d},{ }^{3} \mathrm{~J}_{\mathrm{HH}}=8 \mathrm{~Hz}, 2 \mathrm{H}, \mathrm{Ar}\right)$, $7.42\left(\mathrm{~d},{ }^{3} \mathrm{~J}_{\mathrm{HH}}=8 \mathrm{~Hz}, 2 \mathrm{H}, \mathrm{Ar}\right), 2.72-4.31\left(\mathrm{~m}\right.$ br, $29 \mathrm{H}$, ring $\mathrm{NCH}_{2}, \mathrm{CH}_{2} \mathrm{C}=\mathrm{O}, \mathrm{CH}_{2} \mathrm{Ar}$, $\left.\mathrm{CHCH}_{3}\right), 1.28 \mathrm{ppm}\left(\mathrm{m}, 12 \mathrm{H}, \mathrm{CHCH}_{3}\right) ; \mathrm{m} / z$ (ESMS EI+): $824\left(100 \%,\left[\mathrm{M}+\mathrm{H}^{+}\right]^{+}\right) ; v_{\max }$ (iTR): $3169(\mathrm{NH}), 1727\left(\mathrm{CO}_{2}\right), 1617(\mathrm{C}=\mathrm{ONH}), 1455,1346,1253,1155,957,821,751$ $\mathrm{cm}^{-1}$. 


\section{General procedure for the preparation of $\mathrm{Ln}^{3+}$ chelates}

Europium triflate $(15 \mathrm{mg}, 24.6 \mathrm{mmol})$ and $\mathbf{1}(20 \mathrm{mg}, 22.3 \mathrm{mmol})$ were dissolved in water and the $\mathrm{pH}$ adjusted to 6 by addition of $\mathrm{NaOH}$ (1 $1 \mathrm{~m}$ aqueous solution). The resulting solution was heated at $60 \mathrm{C}$ for $24 \mathrm{~h}$ and then allowed to cool to room temperature. After filtration through a $20 \mathrm{~mm}$ syringe filter the reaction mixed was injected directly onto a preparative HPLC system for purification. Chelates were obtained by lyophilization of the fraction containing the major reaction product.

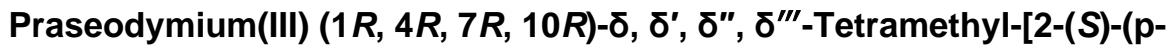
nitrobenzyl)-1,4,7,10-tetraazacyclododecane]-1,4,7,10-tetraacetateacetamide (HPrSRRRR-1)

$\mathrm{R}_{\mathrm{T}}=30.20 \mathrm{~min} ; \mathrm{m} / z$ (ESMS EI-): $963\left(100 \%,\left[\mathrm{M}^{-} \mathrm{H}^{+}\right]^{-}\right)$an appropriate isotope pattern was observed.

Europium(III) (1R, 4R, 7R, 10R)-ס, $\delta^{\prime}, \delta^{\prime \prime}, \delta^{\prime \prime \prime}-$ Tetramethyl-[2-(S)-(p-nitrobenzyl)-1,4,7,10tetraazacyclododecane]-1,4,7,10-tetraacetateacetamide (HEuS-RRRR-1)

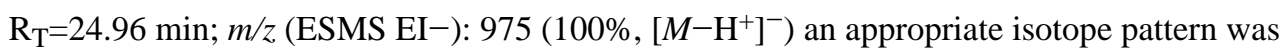
observed.

Ytterbium(III) (1R, 4R, 7R, 10R)-ס, $\delta^{\prime}, \delta^{\prime \prime}, \delta^{\prime \prime \prime}-$ Tetramethyl-[2-(S)-(p-nitrobenzyl)-1,4,7,10tetraazacyclododecane]-1,4,7,10-tetraacetateacetamide (HYbS-RRRR-1)

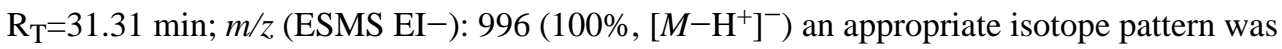
observed.

Praseodymium(III) (1S, 4S, 7S, 10S)-ס, $\delta^{\prime}, \delta^{\prime \prime}, \delta^{\prime \prime \prime}$-Tetramethyl-[2-(S)-(p-nitrobenzyl)-1,4,7,10tetraazacyclododecane]-1,4,7,10-tetraacetateacetamide (HPrS-SSSS-1)

$\mathrm{R}_{\mathrm{T}}=25.33 \mathrm{~min} ; \mathrm{m} / z$ (ESMS EI-): $963\left(100 \%,\left[\mathrm{M}^{-} \mathrm{H}^{+}\right]^{-}\right)$an appropriate isotope pattern was observed.

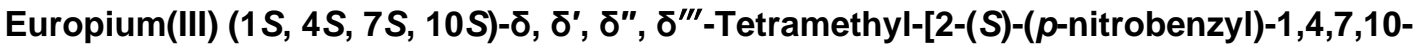
tetraazacyclododecane]-1,4,7,10-tetraacetateacetamide (HEuS-SSSS-1)

$\mathrm{R}_{\mathrm{T}}=30.24 \mathrm{~min} ; \mathrm{m} / z$ (ESMS EI-): $975\left(100 \%,\left[\mathrm{M}^{-} \mathrm{H}^{+}\right]^{-}\right)$an appropriate isotope pattern was observed.

Ytterbium(III) (1S, 4S, 7S, 10S)-ס, $\delta^{\prime}, \delta^{\prime \prime}, \delta^{\prime \prime \prime}-$ Tetramethyl-[2-(S)-(p-nitrobenzyl)-1,4,7,10tetraazacyclododecane]-1,4,7,10-tetraacetateacetamide (HYbS-SSSS-1)

$\mathrm{R}_{\mathrm{T}}=20.45 \mathrm{~min} ; \mathrm{m} / z$ (ESMS EI-): $996\left(100 \%,\left[\mathrm{M}^{-} \mathrm{H}^{+}\right]^{-}\right)$an appropriate isotope pattern was observed.

\section{CEST fitting}

CEST spectra were recorded at six different $B_{1}$ powers for each chelate: $42.7 \mu \mathrm{T}, 36.3 \mu \mathrm{T}$, $34.3 \mu \mathrm{T}, 30.1 \mu \mathrm{T}, 27.4 \mu \mathrm{T}$, and $24.3 \mu \mathrm{T}$ (see Figure $\mathrm{S} 1$ in the Supporting Information). The water proton exchange kinetics for each SAP isomer were determined by plotting the magnetization at the CEST peak minimum as a function of the initial magnetization $\left(\mathrm{M}_{\mathrm{Z}}\right.$ / $\left.\left(\mathrm{M}_{0}-\mathrm{M}_{\mathrm{Z}}\right)\right)$ against the reciprocal of the square of the $\mathrm{B}_{1}$ power expressed in $\mathrm{rad} \mathrm{s}^{-1}\left(1 \omega^{2}\right)$ (Figure 6). The data were then fitted by using linear regression analysis and the intercept of the line with the $x$ axis provides the water exchange rate directly. ${ }^{29]}$

The CEST spectra were then fitted to the Bloch equations modified for exchange as previously described. ${ }^{[28]}$ A 2-pool model was used to fit the data for EuS-RRRR-1 
representing the bulk water pool, the bound or shifted water pool. The inclusion of a pool for the amide protons was found not to affect the fitting and therefore excluded from the all fitting models. A 3-pool model was used to fit the data for EuS-RRRR-1 representing the bulk water, the bound water or shifted water associated with the SAP isomer and the bound or shifted water associated with the TSAP isomer.

The pre-saturation power $\left(\mathrm{B}_{1}\right)$ was held fixed during fitting. The water proton exchange lifetime $\left(\tau_{\mathrm{M}}{ }^{\mathrm{H}}\right)$ was constrained to lie within $10 \%$ of the value determined by the $\omega$-fitting. In initial fittings the concentration of each pool was deconstrained to reflect the confidence level of the concentration determination. $T_{1}$ values for the bulk water pool were determined experimentally using an inversion recovery pulse sequence and held fixed during fitting. $\mathrm{T}_{1}$ values for the other pools could not be determined by direct measurement owing to the low chelate concentrations of each sample. The $\mathrm{T}_{1} \mathrm{~s}$ of these pools and all $\mathrm{T}_{2}$ values were allowed to float over the range of values previously found in CEST fitting routines in EuDOTA-tetramide chelates. ${ }^{[31]}$ The value of $\tau_{\mathrm{M}}{ }^{\mathrm{H}}$ for the TSAP isomer, which does appear to influence the shape of the direct saturation peak at $0 \mathrm{ppm}$ (witness the downfield edge of the peak), was constrained to have a ratio of between $1 / 40$ and $1 / 60$ of the $\tau_{M}{ }^{H}$ value of the SAP isomer. This ratio is consistent with previously reported behavioral patterns in this type of chelate.

Fitting the CEST data acquired at $\mathrm{B}_{1}=1282.8 \mathrm{~Hz}$ afforded a good fit to the data for EuS$R R R R-1$. However, a suitable fit to the S-SSSS-isomer could not be obtained when the concentration was constrained as described (see Figure S2 in the Supporting Information). Only when the concentration of the highly shifted pool is allowed to float and fit to values 3.7 times higher than the $13.7 \mu \mathrm{m}$ chelate concentration is an adequate fit achieved.

\section{Supplementary Material}

Refer to Web version on PubMed Central for supplementary material.

\section{Acknowledgments}

The authors acknowledge grant support from the National Institutes of Health (EB-11687 (M.W.); RR-02584 and CA-115531 (A.D.S.)); ONAMI (N00014-11-1-0193), the M. J. Murdock Charitable Trust and the Robert A Welch Foundation (AT-584).

\section{References}

[1]. Woods M, Kovacs Z, Zhang S, Sherry AD. Angew. Chem. 2003; 115:6069.Angew. Chem. Int. Ed. 2003; 42:5889.

[2]. Woods M, Botta M, Avedano S, Wang J, Sherry AD. Dalton Trans. 2005:3829. [PubMed: 16311635]

[3]. Aime S, Botta M, Ermondi G. Inorg. Chem. 1992; 31:4291.

[4]. Hoeft S, Roth K. Chem. Ber. 1993; 126:869.

[5]. Aime S, Barge A, Bruce JI, Botta M, Howard JAK, Moloney JM, Parker D, de Sousa AS, Woods M. J. Am. Chem. Soc. 1999; 121:5762.

[6]. Dunand FA, Aime S, Merbach AE. J. Am. Chem. Soc. 2000; 122:1506.

[7]. Woods M, Aime S, Botta M, Howard JAK, Moloney JM, Navet M, Parker D, Port M, Rousseaux O. J. Am. Chem. Soc. 2000; 122:9781.

[8]. Woods M, Woessner DE, Sherry AD. Chem. Soc. Rev. 2006; 35:500. [PubMed: 16729144]

[9]. Zhang S, Winter P, Wu K, Sherry AD. J. Am. Chem. Soc. 2001; 123:1517. [PubMed: 11456734]

[10]. Miller KJ, Saherwala AA, Webber BC, Wu Y, Sherry AD, Woods M. Inorg. Chem. 2010; 49:8662. [PubMed: 20812752] 
[11]. Aime S, Botta M, Dickins RS, Maupin CL, Parker D, Riehl JP, Williams JAG. J. Chem. Soc. Dalton Trans. 1998:881.

[12]. Baranyai Z, Brücher E, Ivanyi T, Kiraly R, Lazar I, Zekany L. Helv. Chim. Acta. 2005; 88:604.

[13]. Terreno E, Daniela D. Castelli, Cravotto G, Milone L, Aime S. Invest. Radiol. 2004; 39:235. [PubMed: 15021328]

[14]. Zhang S, Malloy CR, Sherry AD. J. Am. Chem. Soc. 2005; 127:17572. [PubMed: 16351064]

[15]. Woods M, Caravan P, Geraldes CFGC, Greenfield MT, Kiefer GE, Lin M, McMillan K, Prata MIM, Santos AC, Sun X, Wang J, Zhang S, Zhao P, Sherry AD. Invest. Radiol. 2008; 43:861. [PubMed: 19002058]

[16]. Sherry AD, Caravan P, Lenkinski RE. J. Magn. Reson. Imaging. 2009; 30:1240. [PubMed: 19938036]

[17]. Schmidt U, Kroner M, Griesser H. Synthesis. 1991:294.

[18]. Aime S, Botta M, Fasano M, Marques MPM, Geraldes CFGC, Pubanz D, Merbach AE. Inorg. Chem. 1997; 36:2059. [PubMed: 11669824]

[19]. Vipond J, Woods M, Zhao P, Tircso G, Ren JM, Bott SG, Ogrin D, Kiefer GE, Kovacs Z, Sherry AD. Inorg. Chem. 2007; 46:2584. [PubMed: 17295475]

[20]. Mani T, Tircso G, Zhao P, Sherry AD, Woods M. Inorg. Chem. 2009; 48:10338. [PubMed: 19799440]

[21]. Dickins RS, Batsanov AS, Howard JAK, Parker D, Puschmann H, Salamano S. Dalton Trans. 2004:70. [PubMed: 15356744]

[22]. Dickins RS, Howard JAK, Moloney JM, Parker D, Peacock RD, Siligardi G. Chem. Commun. 1997:1747.

[23]. Dickins RS, Howard JAK, Lehmann CW, Moloney J, Parker D, Peacock RD. Angew. Chem. 1997; 109:541.Angew. Chem. Int. Ed. Engl. 1997; 36:521.

[24]. Dickins RS, Howard JAK, Maupin CL, Moloney JM, Parker D, Riehl JP, Siligardi G, Williams JAG. Chem. Eur. J. 1999; 5:1095.

[25]. Dickins RS, Aime S, Batsanov AS, Beeby A, Botta M, Bruce JI, Howard JAK, Love CS, Parker D, Peacock RD, Puschmann H. J. Am. Chem. Soc. 2002; 124:12697. [PubMed: 12392417]

[26]. Gunnlaugsson T, Davies RJH, Nieuwenhuyzen M, O’Brien JE, Stevenson CS, Mulready S. Polyhedron. 2003; 22:711.

[27]. Thompson AL, Parker D, Fulton DA, Howard JAK, Pandya SU, Puschmann H, Senanayake K, Stenson PA, Badari A, Botta M, Avedano S, Aime S. Dalton Trans. 2006:5605. [PubMed: 17225897]

[28]. Woessner DE, Zhang S, Merritt ME, Sherry AD. Magn. Reson. Med. 2005; 53:790. [PubMed: 15799055]

[29]. Dixon WT, Ren J, Lubag AJM, Ratnakar J, Vinogradov E, Hancu I, Lenkinski RE, Sherry AD. Magn. Reson. Med. 2010; 63:625. [PubMed: 20187174]

[30]. Wu Y, Zhou Y, Ouari O, Woods M, Zhao P, Soesbe TC, Kiefer GE, Sherry AD. J. Am. Chem. Soc. 2008; 130:13854. [PubMed: 18817395]

[31]. Woods M, Woessner DE, Zhao P, Pasha A, Yang M-Y, Huang C-H, Vasalitiy O, Morrow JR, Sherry AD. J. Am. Chem. Soc. 2006; 128:10155. [PubMed: 16881645] 


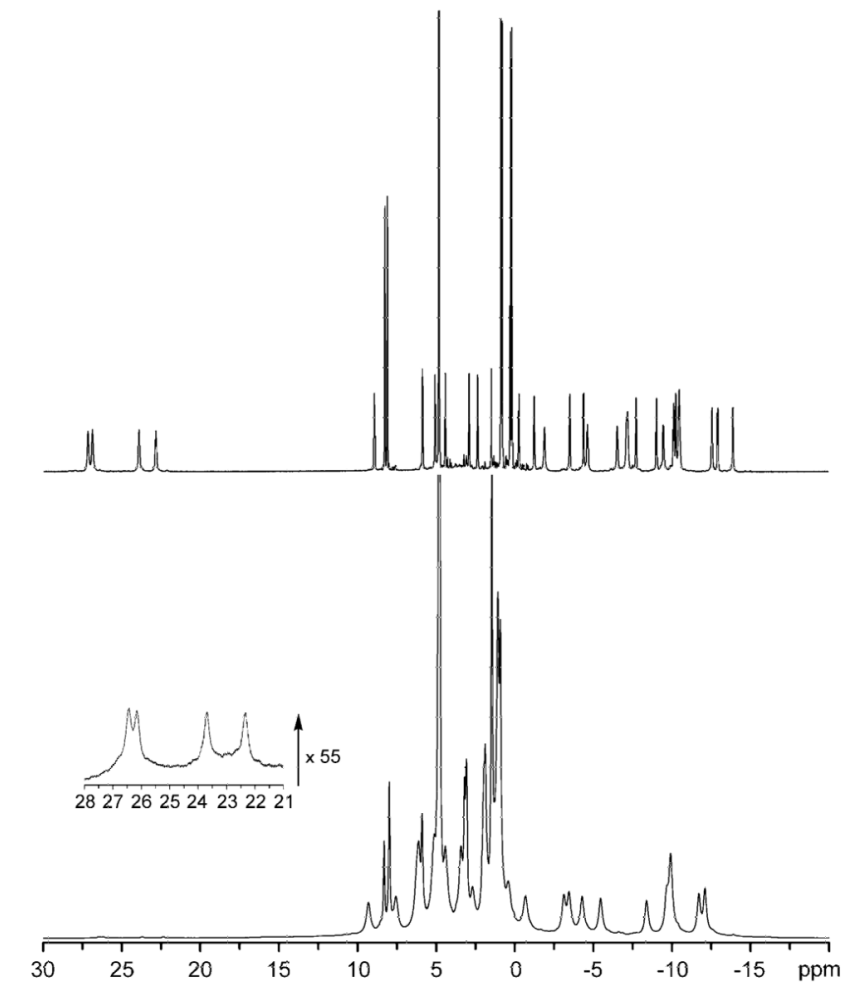

Scheme 1.

The preparation of the two diastereoisomeric ligands $\mathbf{1}$. Reagents and conditions: $S-R R R R-\mathbf{1}$, $\mathrm{R}=\mathrm{Et}$ : i. $\mathrm{BrCH}_{2} \mathrm{COBr} / \mathrm{K}_{2} \mathrm{CO}_{3} / \mathrm{CH}_{2} \mathrm{Cl}_{2} / 0^{\circ} \mathrm{C}$; ii. $S$-NB-cyclen $/ \mathrm{K}_{2} \mathrm{CO}_{3} / \mathrm{MeCN} / 60^{\circ} \mathrm{C}$; iii. $\mathrm{NaOH} /$ $\mathrm{H}_{2} \mathrm{O} / \mathrm{THF}$; iv. $\mathrm{HCl}$ : $S$-SSSS-1, $\mathrm{R}=\mathrm{Bn}$ : i. $\mathrm{BrCH}_{2} \mathrm{COBr} / \mathrm{K}_{2} \mathrm{CO}_{3} / \mathrm{CH}_{2} \mathrm{Cl}_{2} / 0^{\circ} \mathrm{C}$; ii. $S$-NB-cyclen/ $\mathrm{K}_{2} \mathrm{CO}_{3} / \mathrm{MeCN} / 60^{\circ} \mathrm{C}$; iii. $\mathrm{BCl}_{3} / \mathrm{CH}_{2} \mathrm{Cl}_{2} / \mathrm{THF}$; iv. $\mathrm{H}_{2} \mathrm{O}$. 


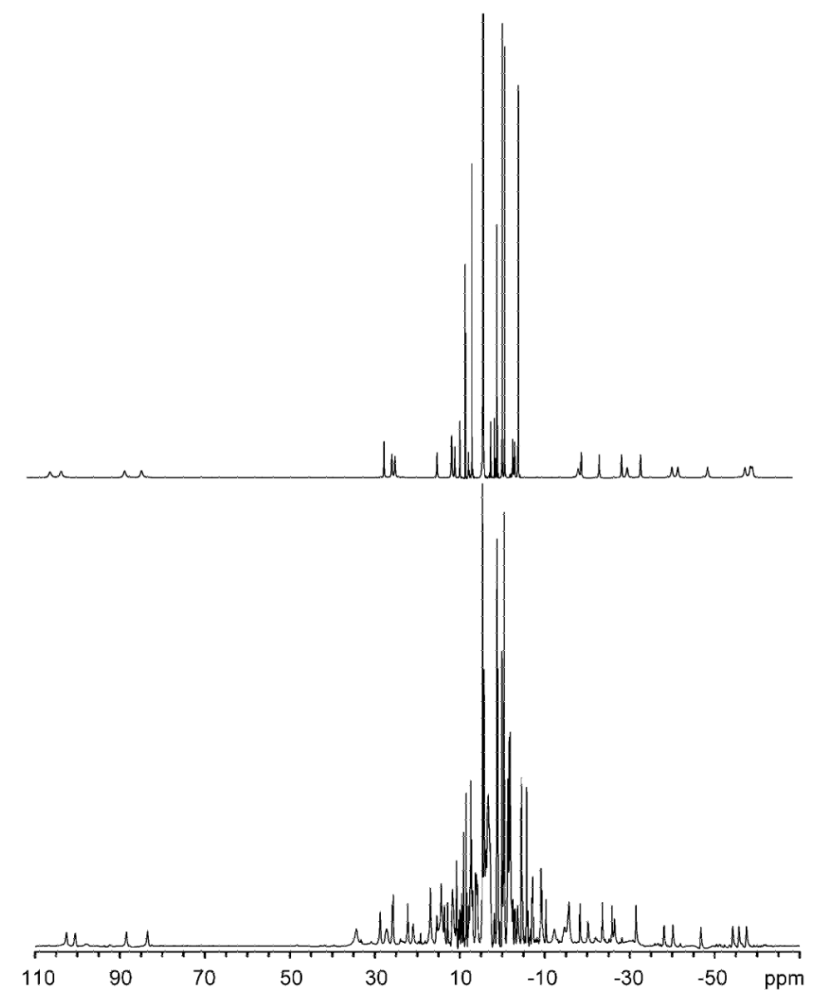

Figure 1.

The ${ }^{1} \mathrm{H}$ NMR spectra of PrS-RRRR-1 (top) PrS-SSSS-1 (bottom) and recorded at $400 \mathrm{MHz}$ and $300 \mathrm{~K}$ in $\mathrm{D}_{2} \mathrm{O}$ at $\mathrm{pD} 4$. The four highly shifted peaks between $\delta=-28$ and $-35 \mathrm{ppm}$ (top) and $\delta=-10$ and $-16 \mathrm{ppm}$ (bottom), are characteristic of the shifts of the $a x^{\mathrm{S}}$ protons in SAP and TSAP isomers of PrDOTA-tetraamide chelates, respectively. 
$\alpha$-substituted amides

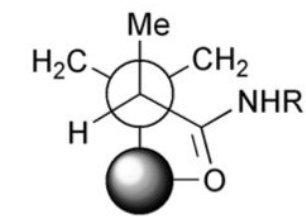

$\Lambda$-helicity - favored

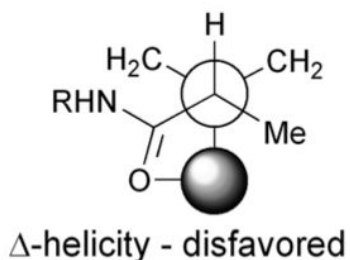

$\Delta$-helicity - disfavored

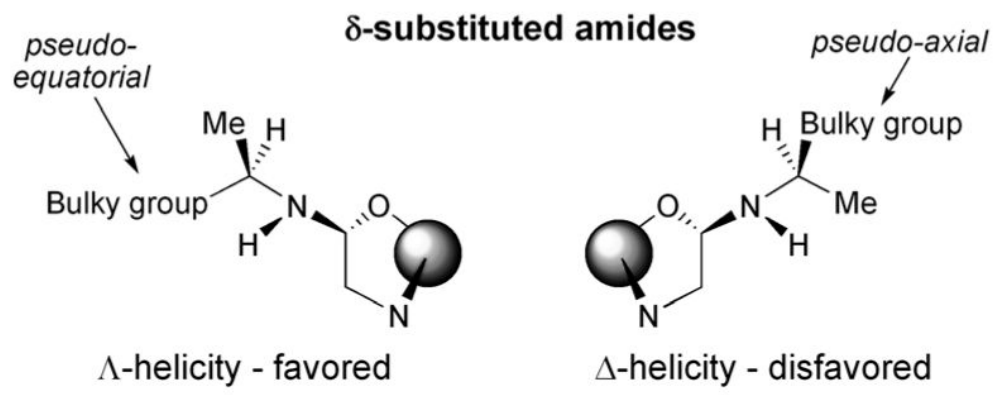

Figure 2.

The ${ }^{1} \mathrm{H}$ NMR spectra of EuS-RRRR-1 (top), EuS-SSSS-1 (bottom) recorded at $400 \mathrm{MHz}$ and $300 \mathrm{~K}$ in $\mathrm{D}_{2} \mathrm{O}$ at $\mathrm{pD}$ 4. The four shifted peaks between 22 and 27 ppm (both spectra) and 7 and $10 \mathrm{ppm}$ (bottom) are typical of those observed for the SAP and TSAP isomers of EuDOTA-tetraamide chelates, respectively. 
Carney et al.

Page 14

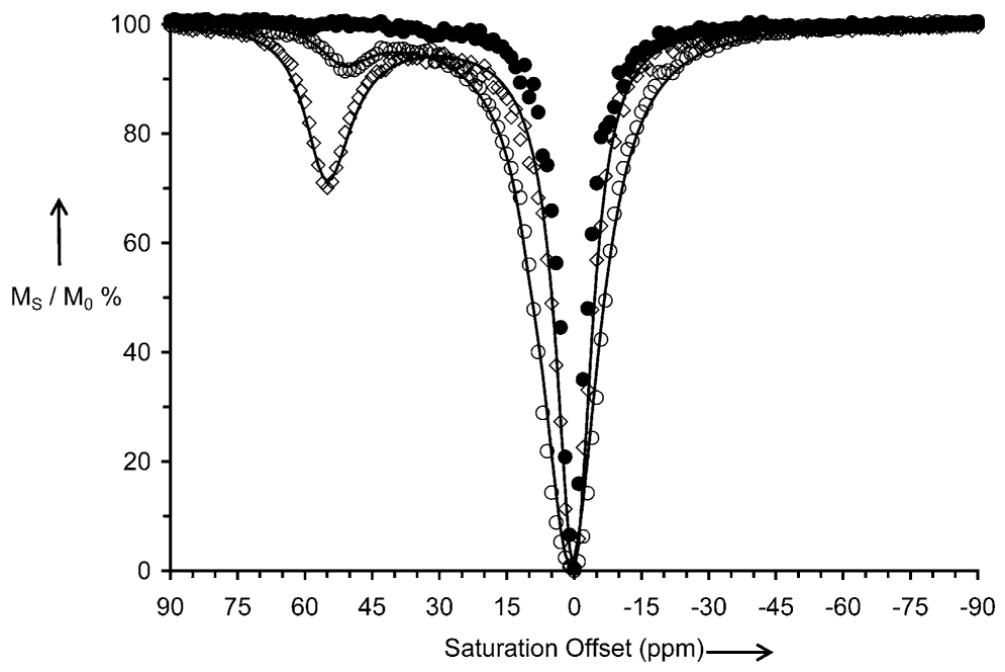

Figure 3.

The ${ }^{1} \mathrm{H}$ NMR spectra of YbS-RRRR-1 (top), YbS-SSSS-1 (bottom) recorded at $400 \mathrm{MHz}$ and $275 \mathrm{~K}$ in $\mathrm{D}_{2} \mathrm{O}$ at $\mathrm{pD} 4$. The four shifted peaks between 82 and $103 \mathrm{ppm}$ (both spectra) and 20 and 35 ppm (bottom) are typical of those observed for the SAP and TSAP isomers of YbDOTA-tetraamide chelates, respectively.

Chemistry. Author manuscript; available in PMC 2012 September 5. 


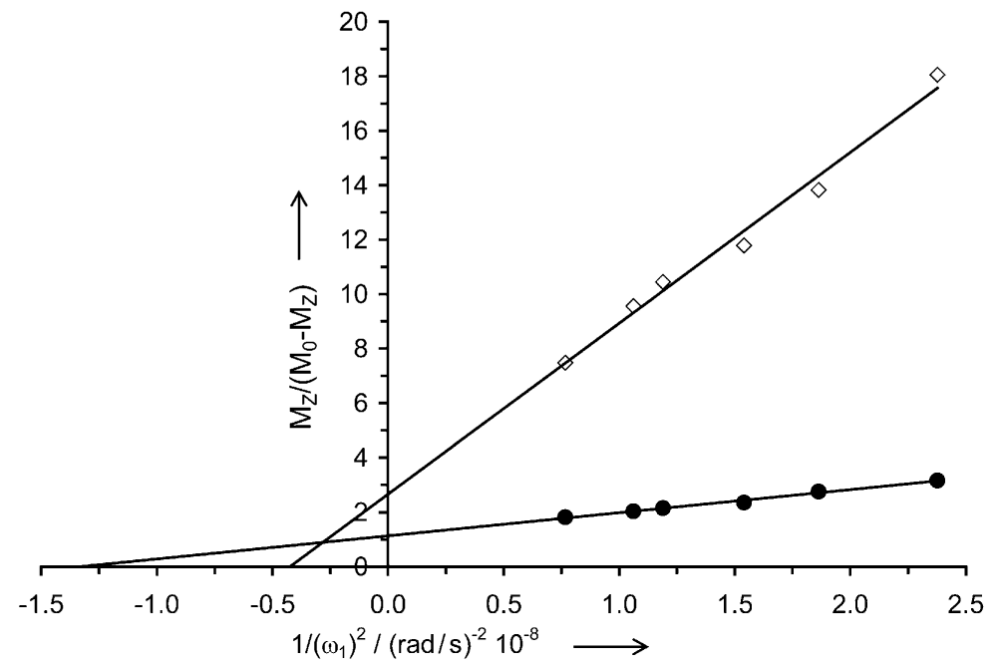

Figure 4.

The orientation of chiral pendant arms and how they are affected by $\alpha$ - (top) and $\delta$ substitution (bottom), in each case the configuration at carbon is $R$. 


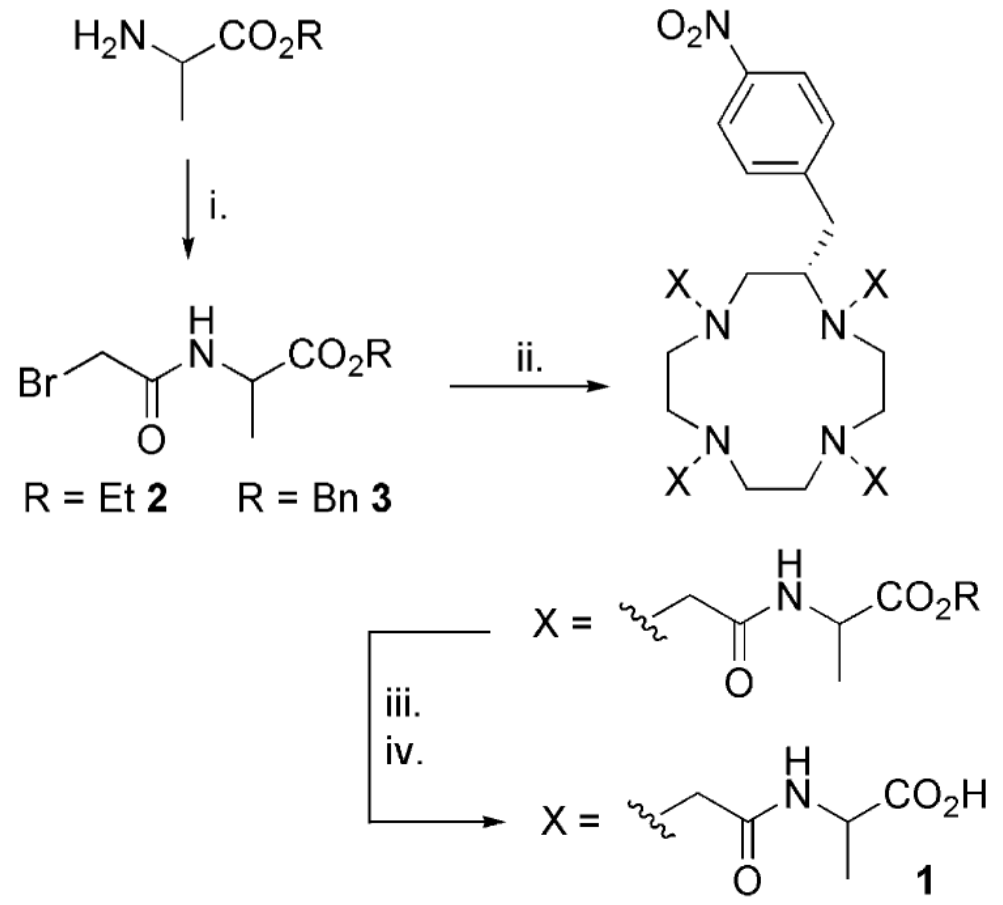

Figure 5.

CEST spectra of solutions of EuS-RRRR-1 ([Eu $\left.{ }^{3+}\right]=[\mathrm{SAP}]=274 \mu_{\mathrm{M}}$ open diamonds; $\left[\mathrm{Eu}^{3+}\right]=[\mathrm{SAP}]=13.7 \mu_{\mathrm{M}}$ closed circles $)$ and EuS-SSSS-1$\left(\left[\mathrm{Eu}^{3+}\right]=274 \mu_{\mathrm{M}},[\mathrm{SAP}]=13.7 \mu_{\mathrm{M}}\right.$ open circles) in $\mathrm{CD}_{3} \mathrm{CN}\left(10 \% \mathrm{H}_{2} \mathrm{O}\right)$ recorded at $400 \mathrm{MHz} ; 298 \mathrm{~K}$; irr. time $=10 \mathrm{~s} ; \mathrm{B}_{1}=30 \mu \mathrm{T}$. 


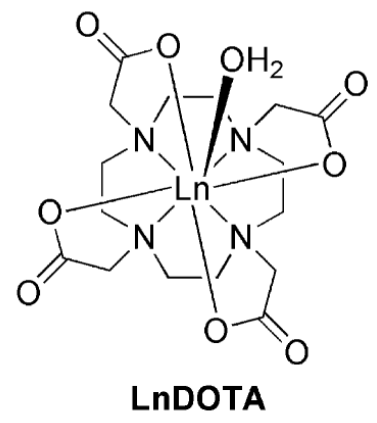

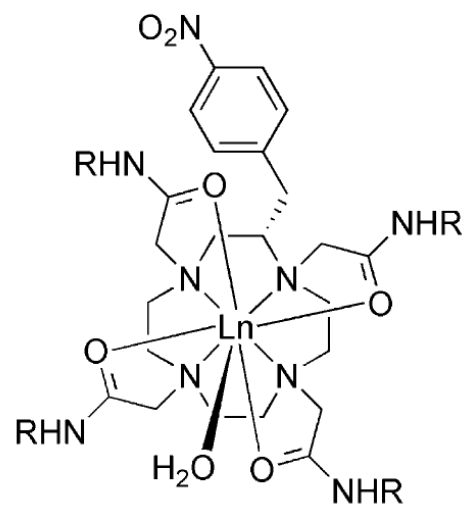

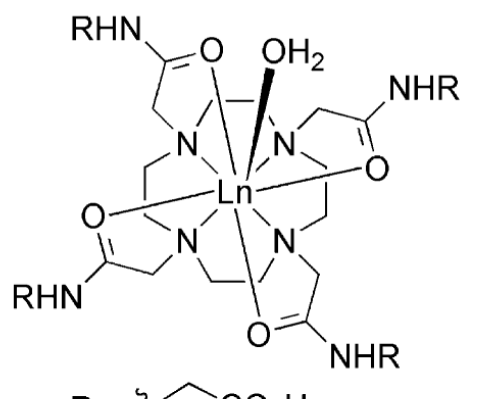<smiles>[R][C+]CCC(=O)O</smiles>

LnDOTAM-Gly

Figure 6.

The $\omega$-plots of EuS-RRRR-1 (filled circles) and EuS-SSSS-1 (open diamonds), data taken from the CEST spectra in Figure S1 in the Supporting Information. The difference in slope of the two lines can be attributed to the difference in SAP isomer concentration between the two samples. The water proton residence lifetimes are afforded by the intercept of the $x$ axis. 